\title{
DIAGNÓSTICO DE FILARÍDEOS EM QUATIS NO PARQUE NACIONAL DO IGUAÇU, FOZ DO IGUAÇU, BRASIL - DADOS PRELIMINARES
}

\author{
FILARIDS DIAGNOSIS IN COATIS OF THE IGUASSU NATIONAL PARK, FOZ DO \\ IGUAÇU, BRAZIL - PRELIMINARY DATA
}

\author{
M. F. D. MORAES ${ }^{1}$, M. X. da SILVA' ${ }^{2}$, A. C. A. ALBUQUERQUE ${ }^{1}$, A. C. DA SILVA ${ }^{1}$, P. C. M. MATOS
} J. H. TEBALDI ${ }^{1}$, E. G. LUX-HOPPE ${ }^{1 *}$

\section{RESUMO}

O Parque Nacional do Iguaçu é um dos últimos remanescentes de mata atlântica da região Sul, e por possuir as Cataratas do Iguaçu, com sua beleza exuberante, atrai anualmente mais de 1.000 .000 de turistas, de vários países, que devido ao contato mais próximo com a natureza, possíveis vetores e potenciais hospedeiros se expõem a um risco de contrair patógenos. Dessa forma, esta pesquisa visou levantar a prevalência de filarioses em quatis (N. nasua) e cães domésticos no referido Parque. Foram capturados 75 quatis e 50 cães domésticos, posteriormente anestesiados com Zoletil ${ }^{\circledR}(5 \mathrm{mg} / \mathrm{kg})$ para colheita de amostras por punção jugular. Foram realizados o teste de Knott, sorológico para Dirofilaria immitis e histoquímica para identificação das microfilárias. O resultado do teste de concentração de Knott em quatis e cães domésticos demonstrou prevalência respectivamente de $81,6 \%$ e $17,7 \%$, e total de cinco morfotipos identificados; no teste imunológico para Dirofilaria immitis, demonstrou-se prevalência de $1,29 \%$ em quatis e $22 \%$ em cães. A histoquímica das microfilárias dos quatis demonstrou a presença de sete padrões de marcação com prevalência de 1,29\% para D.immitis, 10,6\% para Dirofilaria repens e Acantocheilonema reconditum, 26,7\% para os gêneros Mansonella sp. e 8\% para Brugia sp, além de dois morfotipos não identificados. As três espécies identificadas infectando quatis no Parque Nacional do Iguaçu, tem potencial zoonótico, com inúmeros casos humanos no mundo. Novas espécies do gênero Brugia vêm sendo relatadas nas Américas e incriminadas como causadoras de filarioses humanas nos Estados Unidos, além do gênero Mansonella que possui espécies de grande potencial zoonótico no Norte do Brasil. Assim, essa pesquisa relata a diversidade de filarídeos com potencial zoonótico infectando quatis no Parque Nacional do Iguaçu e afirma a necessidade de uma vigilância ativa para que não haja subnotificações dessas parasitoses em cães domésticos e também em humanos residentes nessa região.

PALAVRAS-CHAVE: CARNÍVOROS. POTENCIAL ZOONÓTICO. HISTOQUÍMICA.

AGRADECIMENTOS: FAPESP

ÁREA TEMÁTICA: Doenças parasitárias

\footnotetext{
${ }^{1}$ Faculdade de Ciências Agrárias e Veterinárias da Universidade Estadual Paulista (UNESP) - Câmpus de Jaboticabal

${ }^{2}$ Projeto Carnívoros do Iguaçu - Parque Nacional do Iguaçu - Foz do Iguaçu - PR

${ }^{3}$ Universidade Federal Rural do Rio de Janeiro - Seropedica - RJ

*e.hoppe@gmail.com
} 